\title{
Scalable culture techniques to generate large numbers of purified human Schwann cells for clinical trials in human spinal cord and peripheral nerve injuries
}

\author{
Aisha Khan, MSc, MBA, ${ }^{1,3}$ Anthony Diaz, MS, ${ }^{1,2}$ Adriana E. Brooks, MS, ${ }^{1,3}$ S. Shelby Burks, MD, ${ }^{1,2}$ \\ Gagani Athauda, MD, ${ }^{7}$ Patrick Wood, PhD, ${ }^{1,2}$ Yee-Shuan Lee, PhD, ${ }^{3}$ Risset Silvera, BS, ${ }^{1,3}$ \\ Maxwell Donaldson, BA, ${ }^{1,3}$ Yelena Pressman, MS, ${ }^{1}$ Kim D. Anderson, PhD, ${ }^{8}$ \\ Mary Bartlett Bunge, PhD, ${ }^{1,2,4}$ Damien D. Pearse, PhD, ${ }^{1-3,6}$ W. Dalton Dietrich, $\mathrm{PhD},{ }^{1,2,4,5}$ \\ James D. Guest, MD, PhD, ${ }^{1,2}$ and Allan D. Levi, MD, $\mathrm{PhD}^{1,2}$ \\ ${ }^{1}$ The Miami Project to Cure Paralysis, ${ }^{2}$ Department of Neurological Surgery, ${ }^{3}$ nterdisciplinary Stem Cell Institute, and \\ Departments of ${ }^{4}$ Cell Biology and ${ }^{5}$ Neurology, University of Miami Miller School of Medicine, Miami; ${ }^{6}$ Bruce W. Carter Department \\ of Veterans Affairs, Veterans Affairs Medical Center, Miami; '7Department of Cellular Biology and Pharmacology, Herbert Wertheim \\ College of Medicine, Florida International University, Miami, Florida; and ${ }^{8}$ Department of Physical Medicine and Rehabilitation, \\ MetroHealth Medical Center, Institute for Functional Restoration, Case Western Reserve University School, Cleveland, Ohio
}

\begin{abstract}
OBJECTIVE Schwann cells (SCs) have been shown to play an essential role in axon regeneration in both peripheral nerve injuries (PNIs) and spinal cord injuries (SCls). The transplantation of SCs as an adjunctive therapy is currently under investigation in human clinical trials due to their regenerative capacity. Therefore, a reliable method for procuring large quantities of SCs from peripheral nerves is necessary. This paper presents a well-developed, validated, and optimized manufacturing protocol for clinical-grade SCs that are compliant with Current Good Manufacturing Practices (CGMPs).

METHODS The authors evaluated the SC culture manufacturing data from 18 clinical trial participants who were recruited for autologous SC transplantation due to subacute $\mathrm{SCl}(n=7)$, chronic $\mathrm{SCl}(n=8)$, or PNIs $(n=3)$. To initiate autologous SC cultures, a mean nerve length of $11.8 \pm 3.7 \mathrm{~cm}$ was harvested either from the sural nerve alone $(n=17)$ or with the sciatic nerve $(n=1)$. The nerves were digested with enzymes and SCs were isolated and further expanded in multiple passages to meet the dose requirements for transplantation.

RESULTS An average yield of $87.2 \pm 89.2$ million cells at $P 2$ and $150.9 \pm 129.9$ million cells at $P 3$ with high viability and purity was produced. Cell counts and rates of expansion increased with each subsequent passage from P0 to P3, with the largest rate of expansion between P2 and P3. Larger harvest nerve lengths correlated significantly with greater yields at P0 and P1 ( $p$ 0.05). In addition, a viability and purity above $90 \%$ was sustained throughout all passages in nearly all cell products.
\end{abstract}

CONCLUSIONS This study presents reliable CGMP-compliant manufacturing methods for autologous SC products that are suitable for regenerative treatment of patients with $\mathrm{SCI}, \mathrm{PNI}$, or other conditions.

https://thejns.org/doi/abs/10.3171/2020.11.SPINE201433

KEYWORDS cell manufacturing; CGMP; Current Good Manufacturing Practices; clinical trials; Schwann cells; spinal cord injury; peripheral nerve injury

$\mathrm{S}$ CHWANN cells (SCs) serve as the primary support cells in the peripheral nervous system (PNS). In peripheral nerve injuries (PNIs), SCs secrete numerous neurotrophic factors that stimulate nerve fiber extension and therefore play an essential role in axon regeneration. ${ }^{1}$
The PNS microenvironment that forms after PNIs has also been shown to promote CNS axonal regeneration. ${ }^{2-6}$ Due to their established reparative potential, SCs present a unique opportunity as a candidate for transplant therapy in spinal cord injuries (SCIs) and long-segmental PNIs. ${ }^{2-4,7-15}$

ABBREVIATIONS Akt = protein kinase B; BSA = bovine serum albumin; CFR = Code of Federal Regulations; CGMPs = Current Good Manufacturing Practices; CM = culture medium; C-SCI = chronic SCl; DMEM = Dulbecco's modified Eagle medium; ErbB3 = epidermal growth factor receptor B3; ERK = extracellular signal-regulated kinase; FBS = fetal bovine serum; IND = Investigational New Drug; PFV = packed fascicle volume; PNI = peripheral nerve injury; PNS = peripheral nervous system; RT-PCR = real-time polymerase chain reaction; SC = Schwann cell; $\mathrm{SCI}=$ spinal cord injury; S-SCI = subacute SCI; VCC = viable cell count. ACCOMPANYING EDITORIAL See pp 133-134. DOI: 10.3171/2021.1.SPINE202065.

SUBMITTED August 2, 2020. ACCEPTED November 24, 2020.

INCLUDE WHEN CITING Published online September 3, 2021; DOI: 10.3171/2020.11.SPINE201433. 


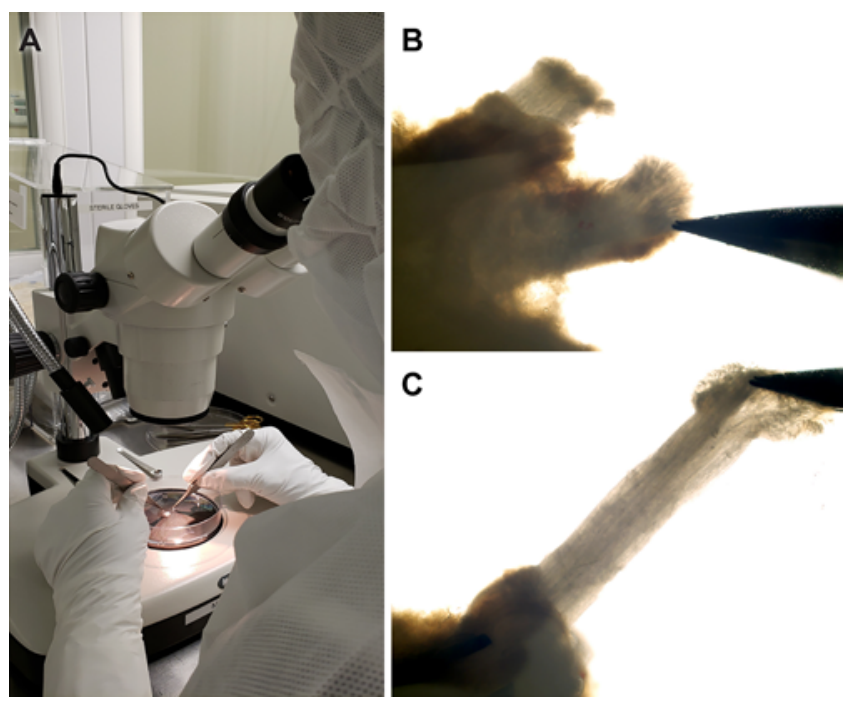

FIG. 1. Fascicle extraction was performed under sterile conditions (A). Fascicles were partly pulled from the epineurium (B) and then cleared of epineurium along the entire length of the nerve $(\mathbf{C})$.

The therapeutic mechanisms of cell transplantation in SCI aim to promote neuroprotection, immunomodulation, glial scar modification, axon regeneration, sprouting, and/ or myelination; reduce blood vessel loss or improve angiogenesis; and establish bridge formation and neural relays. ${ }^{16}$ SCs transplanted into injured rat spinal cords have been shown to reduce cyst size, provide neuroprotection around the injury, promote propriospinal and supraspinal axon regeneration, myelinate axons, and potentially improve functional recovery. ${ }^{17,18}$

SCs can be obtained from human peripheral nerves and then purified and expanded in culture for transplantation into the lesioned spinal cord or transected peripheral nerve. ${ }^{19,20}$ Numerous studies from our institution (the University of Miami) demonstrating the regenerative potential of SCs have contributed to the approval of clinical trials evaluating the safety and efficacy of SC therapy in subacute (S-SCI) and chronic (C-SCI) SCI and PNI by the US FDA. ${ }^{19,21-26}$

Human SCs are considered cellular- and tissue-based products. SC production for clinical studies under Investigational New Drug (IND) applications must therefore be in compliance with the Code of Federal Regulations (CFR), Title 21, Part 1271, which describes the current Good Tissue Practice ${ }^{27}$ and additional requirements. ${ }^{28,29}$ A critical component of these applications is to demonstrate the safety of tissue-based products by providing critical quality attributes and a well-characterized homogenous cell population. Cell expansion protocols defining cell-seeding density, media formulation, and exchange during in vitro cultivation remain laboratoryspecific and are not standardized for any of the above factors.

In this paper we present a culture methodology that is compliant with Current Good Manufacturing Practices (CGMPs) for procuring large populations of SCs from peripheral nerves, which has been developed as a result of decades of study, and we identify the characteristics of
SCs derived from sural nerve biopsies and expanded adequately for clinical trials.

\section{Methods \\ Participants}

Eighteen patients were screened and recruited for 1 of 3 SC transplantation clinical trials: S-SCI $(n=7)$, C-SCI $(n=8)$, and PNIs $(n=3)$. Both the S-SCI and C-SCI trials were conducted under IND no. 14856, and the peripheral nerve trial was conducted under IND no. 18909. All studies were approved by the University of Miami IRB. Participant screening and suitability were in compliance with 21 CFR Part $1271,{ }^{30}$ which involved the review of relevant medical records for risk factors and clinical evidence of communicable diseases. Standard testing for HIV, hepatitis $B$ virus, and hepatitis $C$ virus was performed, as well as a urine pregnancy test for female participants.

\section{CGMP-Compliant Manufacturing}

SC manufacturing was undertaken in CGMP-compliant facilities at our institution. All steps were performed under the strictest sterile conditions in accordance with CGMP regulations. ${ }^{31}$ Our facilities were specifically designed for cellular processing to meet the minimum and more than minimally manipulated manufacturing requirements. Our facilities operate under the government regulations of CGMP that are recognized worldwide for the control and management of manufacturing and quality-control testing of pharmaceutical/biological products and are held to the highest standards set by the FDA.

\section{Nerve Harvesting and Preparation for SC Cultures}

Clinical trial participants underwent minor surgery to harvest a portion of their sural nerve $(5-20 \mathrm{~cm})$ by a single neurosurgeon. The harvested nerve was transported in a sterile container with Belzer's transport media (Static Preservation Solution-1, Organ Recovery Systems, Inc.) to the cell processing facility at $2^{\circ} \mathrm{C}-8^{\circ} \mathrm{C}$.

Within a sterile field and using a dissecting microscope (Fig. 1A), the nerve was cut into $1-\mathrm{cm}$ segments and the excess connective tissue and fat were removed. This length is optimized for pulling fascicles from the epineurium (Fig. 1B and C), and only clean fascicles were transferred (aseptically) to a T-75 flask (Corning). The remaining interfascicular epineurium or connective tissue was also discarded. Culture medium (CM) was added to the flask and then placed in an incubator at $37^{\circ} \mathrm{C}$ with $8 \% \mathrm{CO}_{2}$. The medium was replenished every 2-3 days. $\mathrm{CM}$ was composed of 1× Dulbecco's modified Eagle medium (DMEM; Life Technologies), $10 \%$ fetal bovine serum (FBS; Hyclone, GE Healthcare Life Sciences), $2 \mathrm{mM}$ forskolin (SigmaAldrich), $10 \mathrm{nM}$ human recombinant heregulin $\beta 1$ (PeproTech), $4 \mathrm{mM}$ L-glutamine (Life Technologies), and 0.064 $\mathrm{mg} / \mathrm{ml}$ gentamicin (APP Pharmaceutical/Fresenius Kabi USA).

\section{Enzymatic Dissociation}

Fascicles remained in these culture conditions for 7-9 days, allowing for wallerian degeneration to take place. ${ }^{32}$ 
TABLE 1. Test schedule for human SC clinical product

\begin{tabular}{|c|c|c|c|c|c|c|c|c|}
\hline Test Description & $\begin{array}{c}\text { Nerve } \\
\text { Procurement \& } \\
\text { Transport Medium }\end{array}$ & $\begin{array}{c}\text { Dissection } \\
\text { Media After } \\
\text { Fascicle Pulling }\end{array}$ & $\begin{array}{l}\text { Plating } \\
\text { of } \\
\text { P0 Cells }\end{array}$ & $\begin{array}{c}\text { Harvest } \\
\text { of P1 } \\
\text { Cells }\end{array}$ & $\begin{array}{l}\text { Thawing \& } \\
\text { Plating of } \\
\text { P1 Cells }\end{array}$ & $\begin{array}{c}3 \pm 1 \text { Days } \\
\text { Prior to Final } \\
\text { Harvest }\end{array}$ & $\begin{array}{c}\text { Final } \\
\text { Harvest }\end{array}$ & Postinfusion \\
\hline $\begin{array}{l}\text { Sterility (aerobic, anaerobic, \& fungal } \\
\text { microorganisms) }\end{array}$ & Yes & Yes & - & Yes & - & Yes & Yes & - \\
\hline Mycoplasma & - & - & - & Yes & - & Yes & Yes & - \\
\hline Endotoxin & - & - & - & Yes & - & & Yes & - \\
\hline Gram stain & - & - & - & Yes & - & & Yes & - \\
\hline Phase-contrast microscope observation & - & - & Yes & Yes & Yes & Yes & Yes & - \\
\hline Purity assessment & - & - & - & Yes & - & Yes & Yes & - \\
\hline Cell viability & - & - & Yes & Yes & Yes & Yes & Yes & Yes \\
\hline
\end{tabular}

After this period, all fascicles were collected into a $15-\mathrm{ml}$ tube and centrifuged at $20 \mathrm{~g}$ for 1 minute to estimate the packed fascicle volume (PFV). Seven milliliters of dissociation enzyme solution was then added to every $0.3 \mathrm{ml}$ of $\mathrm{PFV}$ and placed in the incubator overnight at $37^{\circ} \mathrm{C}$ with $8 \% \mathrm{CO}_{2}$. The dissociation enzyme solution was composed of 2 DMC U/ml of neutral protease NB (SERVA Electrophoresis $\mathrm{GmbH}$ ) and $0.5 \mathrm{PZ} \mathrm{U} / \mathrm{ml}$ of collagenase NB1 (SERVA Electrophoresis GmbH) in DMEM supplemented with $3.1 \mathrm{mM} \mathrm{CaCl}$ (International Medication Systems Ltd.). The next day, FBS was added to the fascicles to neutralize the enzymes.

The 15-ml tube was washed with DMEM containing $10 \%$ FBS (D10 medium) and then centrifuged at $150 \mathrm{~g}$ for 5 minutes at $4^{\circ} \mathrm{C}$ to pellet the cells at passage 0 (P0). The $\mathrm{P} 0$ cells were then washed twice with D10 medium and resuspended in CM. The total viable cell number and viability were determined using methods described below in the Cell Viability and Counts section.

\section{SC Expansion}

P0 cells were then plated onto flasks coated with mouse laminin $\left(1 \mathrm{\mu l} / \mathrm{cm}^{2}\right.$; Sigma-Aldrich) in CM. The cells were fed with CM every 3 days, reaching 80\%-90\% confluence after 7 days. Visual inspections of the cultures were monitored at each medium change and at each passage using phase-contrast microscopy. Examination by phasecontrast microscopy allowed for estimation of SC growth (confluence of cultures), identification, and detection of gross microbial contamination, if present. Once they reached confluence, the flasks were rinsed with Hanks' Balanced Salt Solution (Thermo Fisher Scientific) and then incubated in $3 \mathrm{ml}$ of TrypLE Select (Thermo Fisher Scientific) at room temperature for 3-10 minutes. Seven milliliters of D10 medium were added to each flask and all cell suspensions were collected into $50-\mathrm{ml}$ tubes. The tubes were centrifuged at $150 \mathrm{~g}$ for 5 minutes at $4^{\circ} \mathrm{C}$, and P1 cells were resuspended with D10 medium. The viability, total P1 cell count, and purity were determined.

In patients with chronic injuries in whom repair was scheduled for more than 21 days after nerve harvest, cells were cryopreserved at P1 before further expansion. This was performed by first loading 1.5-2 million cells $/ \mathrm{ml}$ in 5 -ml vials with a freezing medium containing $20 \% \mathrm{CM}$,
$70 \%$ FBS, and 10\% dimethyl sulfoxide and then stored in the vapor phase of liquid nitrogen until ready for further expansion. When ready, the appropriate number of vials, as determined by the final required concentration for implantation, were thawed for plating. Once ready, P1 cells were plated onto flasks coated with mouse laminin in CM. The seeding density was increased from 6666 cells $/ \mathrm{cm}^{2}$ to a range of $13,333-20,000$ cells $/ \mathrm{cm}^{2}$. The medium was replenished every 2-3 days, and once the cells reached confluence greater than $80 \%$, they were harvested and replated for another passage or used as a final product. Cells were transplanted at either P2 or P3, depending on the concentration required for transplantation.

\section{Cell Viability and Counts}

Cell counts and viability were determined whenever the cells were harvested for passaging, cryopreservation, or as a final product. Samples of a given cell suspension were separately stained with either SYTO 24 or SYTOX Green (Invitrogen) and loaded into an automated cellcounting instrument (Cellometer Vision, Nexcelom Bioscience Corp.), which then provided counts of dead and total cells. An aliquot of cells was prepared and kept in the same condition as the transplanted cells and viability was determined after infusion.

\section{Purity}

SCs were prepared for flow cytometry at each time point, as shown in Table 1. The cells were washed twice, then blocked with Fc receptor blocking solution for 5 minutes, followed by another wash. The blocking step was repeated before adding the antibody solution (listed in Supplementary Table 1) and incubating for 30 minutes at $4^{\circ} \mathrm{C}$. Cells were washed twice, resuspended with $200 \mu \mathrm{l}$ of eBioscience flow cytometry staining buffer (Invitrogen), and analyzed using a flow cytometer (CytoFLEX, Beckman Coulter). In addition to purity, all products were assessed for predetermined product release criteria (Table 2) as recommended in the FDA guidance for phase 1 INDs. The list of testing and methodology is presented in Table 2.

\section{Sterility}

Sterility testing ${ }^{33}$ consisted of two components: bac- 
TABLE 2. Testing and methodology requirements for final product release

\begin{tabular}{|c|c|c|}
\hline Test & Test Method & Specification \\
\hline \multicolumn{3}{|l|}{ Safety } \\
\hline $\begin{array}{l}\text { Bacterial (aerobic, anaerobic) \& } \\
\text { fungal testing }\end{array}$ & Sterility testing (outsourced to analytical lab) per 21 CFR 610.12 & Sterile \\
\hline Gram stain & Gram stain & Negative \\
\hline Bacterial endotoxin & LAL method by Endosafe PTS & $<0.2 \mathrm{EU} / \mathrm{kg}$ of recipient's body weight \\
\hline \multirow[t]{2}{*}{ Mycoplasma } & RT-PCR & Negative \\
\hline & Culture based per 21 CFR 610.30 & Negative \\
\hline \multicolumn{3}{|l|}{ Purity/identity } \\
\hline Cell count \& viability & Cell count \& viability assay: using SYTO24 and SYTOX Green & VCC $\geq 100-150 \times 10^{6}$ cells, viability $\geq 80 \%$ \\
\hline Purity & FACS & CD271+ cells $\geq 90 \%$ \\
\hline Microscopic exam of cultures & Inverted bright-field microscopy & Bipolar spindle-shaped SCs \\
\hline
\end{tabular}

FACS = fluorescence-activated cell sorting; LAL = limulus amebocyte lysate; PTS = portable testing system.

terial (aerobic, anaerobic) and fungal testing, and Gram stain testing. Samples were collected at time points indicated in Table 1 and sent to WuXi AppTec Laboratories to perform the bacterial and fungal testing using both membrane filtration and immersion methods. Sample processing for bacterial and fungal testing required 21 days and a minimum of 5 days for membrane filtration and immersion methods, respectively. Due to this delay, Gram stain testing was performed on the final harvest for rapid sterility confirmation. Samples were collected during product harvest, and Gram stain tests were performed at the Microbiology Laboratory in the Pathology Department of our institution. Negative Gram staining was a product release criterion.

Bacterial endotoxin testing was performed using the limulus amebocyte lysate assay method on the final product before cryopreservation and after thawing before product release, using the Endosafe portable testing system (Charles River). Final products with an endotoxin amount $\leq 0.2 \mathrm{EU} / \mathrm{ml}$ volume $/ \mathrm{kg}$ recipient body weight of the total product were released for infusion. ${ }^{34}$

Two methods were used to confirm the absence of mycoplasma: point-to-consider, a microbial ${ }^{35}$ culture method performed by WuXi AppTec Laboratories, and a nucleic acid test using real-time polymerase chain reaction (RT$\mathrm{PCR}$ ) performed at our institution.

\section{Pretrial Product Development}

Prior to initiation of the first clinical trial, the product and genetic stability and impurity assessments were evaluated on SCs produced from sural nerves isolated from 3 cadavers.

To assess for residual levels of heregulin $\beta 1$ peptide, mouse laminin, gentamicin, and FBS (determined by detecting bovine serum albumin [BSA] level) following enzymatic dissociation, the second and third washes were collected. Both washes were used to assess residual laminin, and only the third wash was used to assess residual gentamicin and BSA (performed by WuXi AppTec Laboratories). To evaluate residual heregulin, SCs were treated with serum-deprived media containing mitogen for 30 minutes, and the following supernatants were collected: the second and third washes (test articles), DMEM/F12 (negative control), $\mathrm{CM}$ at serial dilutions up to $1: 100,000$ (standard curve), cell culture supernatant exposed to cells (positive control), and CM diluted in the third wash supernatant at 1:10 and 1:100 dilutions (spiking controls). Specific antibodies recognizing the total and phosphorylated forms of ERK (extracellular signal-regulated kinase) 1/2 on tyrosine-204 (P-ERK1/2), Akt (protein kinase B) on serine-473 (P-Akt Ser-473), and ErbB3 (epidermal growth factor receptor B3) on tyrosine-1289 (P-ErbB3 Tyr-1289) were tested by Western blot to detect residual heregulin.

To evaluate genetic abnormalities of P1 and P2 cells, SCs harvested from the donors were sent for karyotyping analysis at our institution's cytogenetic testing laboratory. The genetic stability of SCs after culture manipulation was tested to comply with the FDA recommendation. ${ }^{36,37}$ For product stability, SCs from the donors were cultured and harvested following the manufacturing protocol for clinical use. Five aliquots were prepared and kept on ice, similar to the final clinical product. Viability was measured at the time of release; at 2, 4, 6, and 8 hours after release; and after passage through a $26 \mathrm{~S}$-gauge Hamilton needle.

\section{Data Analysis}

All data are presented as mean \pm standard deviation unless stated otherwise. Statistical tests were performed using GraphPad Prism (version 6.00, GraphPad Software). A p value $<0.05$ was considered statistically significant. One-way ANOVA with Tukey's post hoc test was used for assessing product stability and to compare total viable cell counts (VCCs) and expansion rates for each passage. Simple linear regression analyses were used to explore correlations between a patient's age, nerve length, and PFV with respect to total VCC at P0 and P1.

\section{Results}

A total of 18 patients, 5 females and 13 males, with a mean age of $32.2 \pm 10.8$ years had a mean nerve length of $11.8 \pm 3.7 \mathrm{~cm}$ harvested for an S-SCI $(\mathrm{n}=7), \mathrm{C}-\mathrm{SCI}(\mathrm{n}=8)$, or PNI $(n=3)$ surgery/repair. One patient in the peripheral 
TABLE 3. Summary data for all products

\begin{tabular}{|c|c|c|c|c|c|c|c|c|c|c|c|c|c|}
\hline \multirow[b]{2}{*}{ Patient } & \multirow[b]{2}{*}{ Nerve } & \multirow{2}{*}{$\begin{array}{c}\text { Age } \\
\text { (yrs), } \\
\text { Sex }\end{array}$} & \multirow{2}{*}{$\begin{array}{l}\text { Nerve } \\
\text { Length } \\
(\mathrm{cm})\end{array}$} & \multirow[b]{2}{*}{$\begin{array}{l}\text { PFV } \\
(\mathrm{ml})\end{array}$} & \multicolumn{2}{|c|}{$\mathrm{PO}$} & \multicolumn{2}{|c|}{$\mathrm{P} 1$} & \multicolumn{2}{|c|}{$\mathrm{P} 2$} & \multicolumn{2}{|c|}{ P3 } & \multirow[b]{2}{*}{$\begin{array}{c}\text { Postinjection } \\
\text { Viability }\end{array}$} \\
\hline & & & & & $\begin{array}{l}\text { Count } \\
\left(\times 10^{6}\right)\end{array}$ & $\begin{array}{c}\text { Viability } \\
(\%)\end{array}$ & $\begin{array}{l}\text { Count } \\
\left(\times 10^{6}\right)\end{array}$ & $\begin{array}{c}\text { Viability } \\
(\%)\end{array}$ & $\begin{array}{l}\text { Count } \\
\left(\times 10^{6}\right)\end{array}$ & $\begin{array}{c}\text { Viability } \\
(\%)\end{array}$ & $\begin{array}{l}\text { Count } \\
\left(\times 10^{6}\right)\end{array}$ & $\begin{array}{c}\text { Viability } \\
(\%)\end{array}$ & \\
\hline S-SCI 1 & Sural & $40, M$ & 16.9 & 0.30 & 9.3 & 94.4 & 36.1 & 97.5 & 37.5 & 93.2 & \multicolumn{2}{|c|}{ Transplant at P2 } & 94.3 \\
\hline S-SCl 2 & Sural & $26, M$ & 8.2 & 0.30 & 4.1 & 97.2 & 4.03 & 100 & 12.73 & 99.9 & 11.4 & 94.2 & 87.6 \\
\hline $\mathrm{S}-\mathrm{SCl} 3$ & Sural & $25, M$ & 17 & 0.36 & 7.2 & 97.23 & 26 & 98.2 & 31.3 & 99 & 45.5 & 96.7 & NA \\
\hline S-SCl 4 & Sural & $31, \mathrm{M}$ & 15.5 & 0.40 & 12.0 & 94.5 & 40 & 97.7 & 380.5 & 99.5 & 436.8 & 93.4 & 96.7 \\
\hline S-SCI 5 & Sural & $43, M$ & 13.2 & 0.40 & 12.0 & 92.9 & 53 & 99 & 184.2 & 97.5 & \multicolumn{3}{|c|}{ Discontinued } \\
\hline S-SCI 6 & Sural & $30, M$ & 12.8 & 0.40 & 8.7 & 88.6 & 34 & 97.3 & 146.1 & 95.8 & \multicolumn{2}{|c|}{ Transplant at P2 } & 93.5 \\
\hline S-SCI 7 & Sural & $42, \mathrm{M}$ & 12.3 & 0.30 & 10.85 & 79.9 & 4.6 & 98.7 & 20.5 & 97.2 & \multicolumn{2}{|c|}{ Transplant at P2 } & NA \\
\hline C-SCl 1 & Sural & $47, \mathrm{M}$ & 13.6 & 0.8 & 16.2 & 92.4 & 50 & 97.5 & 85.4 & 98 & 212.4 & 96.6 & 93.8 \\
\hline C-SCl 2 & Sural & $31, F$ & 12.5 & 0.3 & 6.84 & 95.7 & 16.45 & 98.1 & 81.9 & 98 & 306.2 & 97.1 & 95.7 \\
\hline C-SCl 3 & Sural & $53, F$ & 13.3 & 0.4 & 6.56 & 96.7 & 16.4 & 98.1 & 93.6 & 95.1 & \multicolumn{2}{|c|}{ Transplant at P2 } & 79.3 \\
\hline C-SCl 4 & Sural & $28, M$ & 13.3 & 0.5 & 9.86 & 97.5 & 33.95 & 98 & 64.31 & NA & 161.6 & 96.4 & 94.5 \\
\hline C-SCI 5 & Sural & $21, M$ & 13.3 & 0.7 & 5.1 & 89 & 15.4 & 97.7 & 43.7 & 96.1 & 108.96 & 96.3 & 97.7 \\
\hline C-SCI 6 & Sural & $22, \mathrm{M}$ & 13.3 & 0.45 & 11.6 & 94.4 & 81.1 & 97.6 & 108.1 & 95.8 & 193.9 & 93.9 & 94 \\
\hline C-SCI 7 & Sural & $48, M$ & 12.1 & 0.5 & 11.1 & 93.5 & 19.8 & 90.2 & 76.9 & 98.2 & 89 & 94.3 & 97.4 \\
\hline $\mathrm{C}-\mathrm{SCl} 8$ & Sural & $20, M$ & 10 & 0.4 & 12.4 & 96 & 41.72 & 96.9 & 176.8 & 95.6 & \multicolumn{2}{|c|}{ Transplant at P2 } & 97.4 \\
\hline PNI 1 & Sural & $26, F$ & 5 & 0.3 & 1.8 & 96.3 & 9.58 & 99.5 & 8.32 & 99.3 & 19.2 & 99.8 & NA \\
\hline & Sciatic & & 5.7 & 0.32 & 1.56 & 93.5 & 6.7 & 99.4 & 5 & 99.8 & 10 & 99.27 & NA \\
\hline PNI 2 & Sural & $30, F$ & 5 & 0.1 & 2.2 & 96.7 & 13.4 & 98.1 & 81.9 & 97.6 & 271 & 97.8 & 96.2 \\
\hline PNI 3 & Sural & $16, F$ & 5 & 0.15 & 1.88 & 96.8 & 4.3 & 98.6 & 18.6 & 94.9 & 95.6 & 93.9 & NA \\
\hline
\end{tabular}

$\mathrm{NA}=$ not applicable.

nerve trial had an additional $5-\mathrm{cm}$ harvest but from the injured sciatic nerve during the initial trauma visit. The mean PFV was $0.39 \pm 0.16 \mathrm{ml}$ after fascicles were pulled. Data for all patients and products in the trials are listed in Table 3.

The entire manufacturing process from nerve harvest to SC product delivery took approximately $26.0 \pm 3.8$ days, $123.3 \pm 52.0$ days, and $26.5 \pm 3.7$ days for the S-SCI, $\mathrm{C}-\mathrm{SCI}$, and PNI trials, respectively. Three products from the S-SCI trial and two products from the C-SCI trial were transplanted at $\mathrm{P} 2$. All other products were transplanted at $\mathrm{P} 3$. One patient in the S-SCI trial was disqualified prior to transplantation due to a change in neurological status. A schematic flow diagram of the manufacturing processes is shown in Fig. 2.

\section{Cell Yield}

The mean cell counts for harvests at P0, P1, P2, and $\mathrm{P} 3$ were $8.0 \pm 4.3$ million, $26.7 \pm 20.5$ million, $87.2 \pm$ 89.2 million, and $150.9 \pm 129.9$ million, respectively. A mean recovery of $84.1 \% \pm 5.7 \%$ was observed upon thawing among the cells at $\mathrm{P} 1$ that were frozen $(\mathrm{n}=8)$. A clear trend toward higher yields and faster expansion rates with each subsequent passage was observed when cell counts were normalized to a 5-cm nerve harvest (Fig. 3A and B). The fastest expansion rate was observed between P2 and $\mathrm{P} 3$ cultures, which was more than 3 -fold greater than the expansion rate for the $\mathrm{P} 1$ and $\mathrm{P} 2$ cultures $(\mathrm{p}=0.014$; Fig. 3B).

Linear regression analyses demonstrated that length of

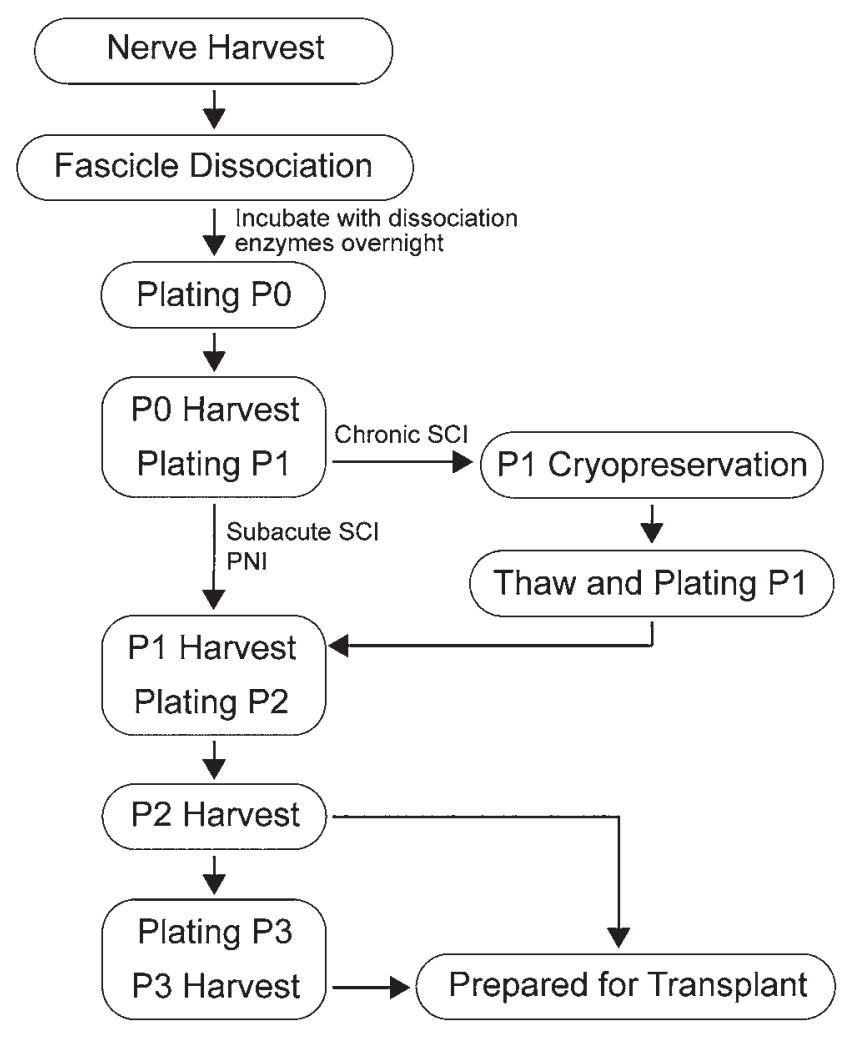

FIG. 2. Schematic flow diagram of the manufacturing process of autologous SCs for participants with S-SCl, C-SCl, or PNI. 

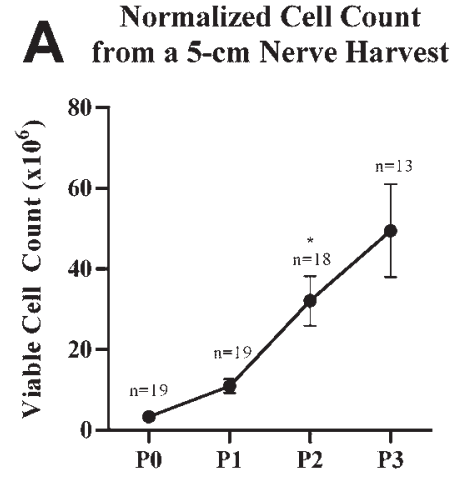

B Normalized Expansion Rate $B$ from a 5-cm Nerve Harvest

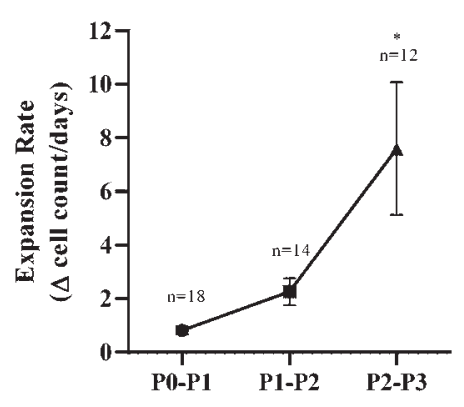

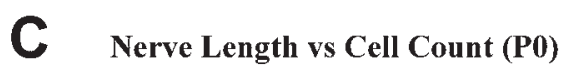

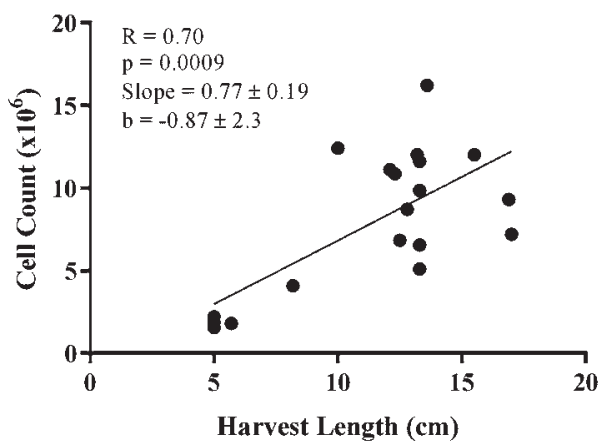

D Nerve Length vs Cell Count (P1)

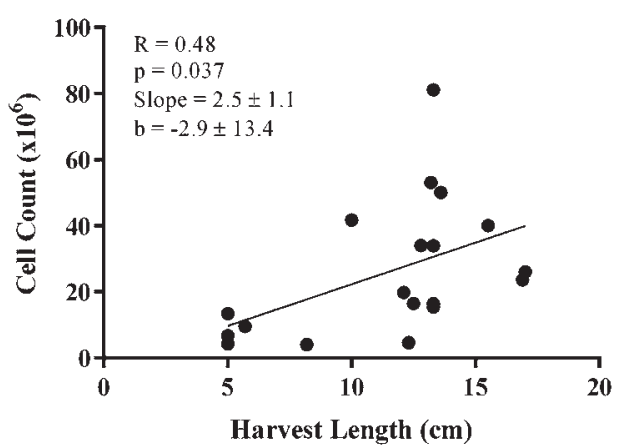

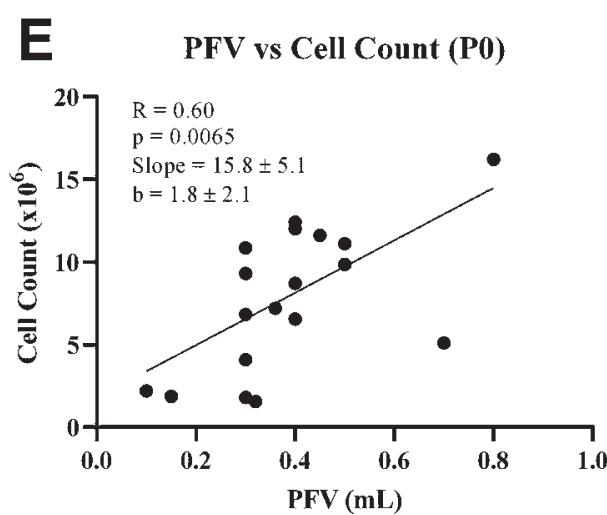

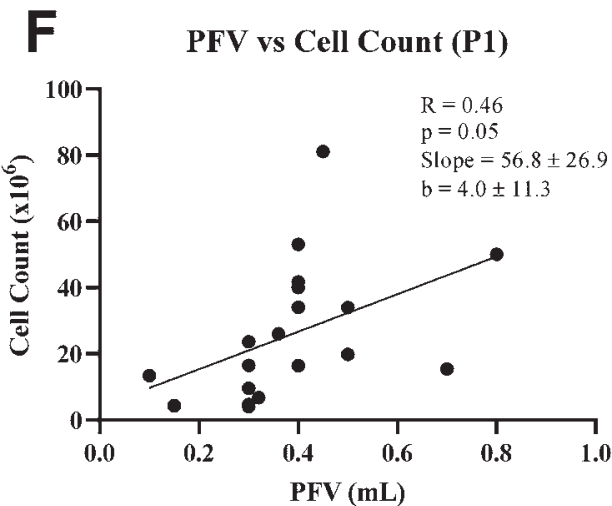

FIG. 3. SC yield. Normalized VCC (A) and normalized expansion rates (B) from a 5-cm nerve harvest increased at every subsequent passage. Longer harvest lengths correlated with higher yields at $P 0(C)$ and $P 1$ (D) on linear regression analysis. Larger PFVs correlated with higher yields at $\mathrm{PO}(\mathrm{E})$ and trended toward higher yields at $\mathrm{P} 1(\mathrm{~F})$. All bars are means $\pm \mathrm{SEM}$. Data were analyzed either by 1 -way ANOVA using a Tukey multiple-comparisons test $(A$ and $B)$ or by simple linear regression analysis $(C-F)$. ${ }^{*} p<0.05$.

the harvested nerve was directly correlated with cell quantity at $\mathrm{P} 0(\mathrm{R}=0.70, \mathrm{p}=0.0009 ;$ Fig. $3 \mathrm{C})$ and $\mathrm{P} 1(\mathrm{R}=0.48$, $\mathrm{p}=0.037 ;$ Fig. 3D), with a stronger correlation at P0. PFVs were also directly correlated with cell counts at $\mathrm{P} 0(\mathrm{R}=$ $0.60, p=0.0065 ;$ Fig. 3E) and trended toward increasing cell counts at $\mathrm{P} 1(\mathrm{R}=0.46, \mathrm{p}=0.05$; Fig. 3F), although not statistically significant. Linear regressions were not run on $\mathrm{P} 2$ or $\mathrm{P} 3$ as not all frozen $\mathrm{P} 1$ cells from the C-SCI patients were used for expansion to P2. No statistically significant correlations between age and cell count or between age, nerve length, and PFV with the expansion rate were observed.

\section{Viability, Purity, and Sterility}

The mean viability rates for harvests at $\mathrm{P} 0, \mathrm{P} 1, \mathrm{P} 2$, and P3 were $93.9 \% \pm 4.2 \%, 97.8 \% \pm 2.0 \%, 97.1 \% \pm 1.9 \%$, and $95.9 \% \pm 2.6 \%$, respectively. The viability in all SC cultures remained $>90 \%$ from $\mathrm{P} 1$ to $\mathrm{P} 3$ and at the time of release (Table 3). The postinfusion viability was also measured $(93.7 \% \pm 5.1 \%)$ to ensure stability of cells at the time of transplantation.

Immunofluorescence on the first three products showed that all SCs were stained positive for S100 and expressed a typical spindle-shaped morphology from passage 1 to 3 (Fig. 4). Fibronectin-positive cells were only observed in P1 cultures. A purity $>90 \%$ was observed in nearly all P1-
P3 SC cultures, as confirmed by high expression of CD271 and low expression of CD14, CD31, CD45, and CD90 on flow cytometry (Fig. 4).

The Gram stains and mycoplasma (RT-PCR and pointto-consider) tests were negative for all SC products that were transplanted. The final endotoxin levels were less than $0.2 \mathrm{EU} / \mathrm{kg}$ for all clinical products. Sterility samples collected from the final product were also negative for aerobic, anaerobic, and fungal organisms.

\section{Pretrial Product Assessments}

Product stability experiments performed with cadaver nerves demonstrated a stable viability up to 8 hours postrelease and after passage through a loading syringe (Fig. 5, left). The purpose of these experiments was to establish the viable therapeutic window after preparation to account for flexibility in transplantation time during the procedure.

The genetic stability assessment on P0 and P1 SCs harvested from cadaver nerves was performed via G-banding karyotype analysis to detect numerical and inter- and intrachromosomal abnormalities. No chromosomal abnormalities were detected at the 350- to 450-band resolution. However, genomic aberrations such as microdeletion/microduplication, subtle structural rearrangement, and lowdegree mosaicism were not ruled out with this analysis. 

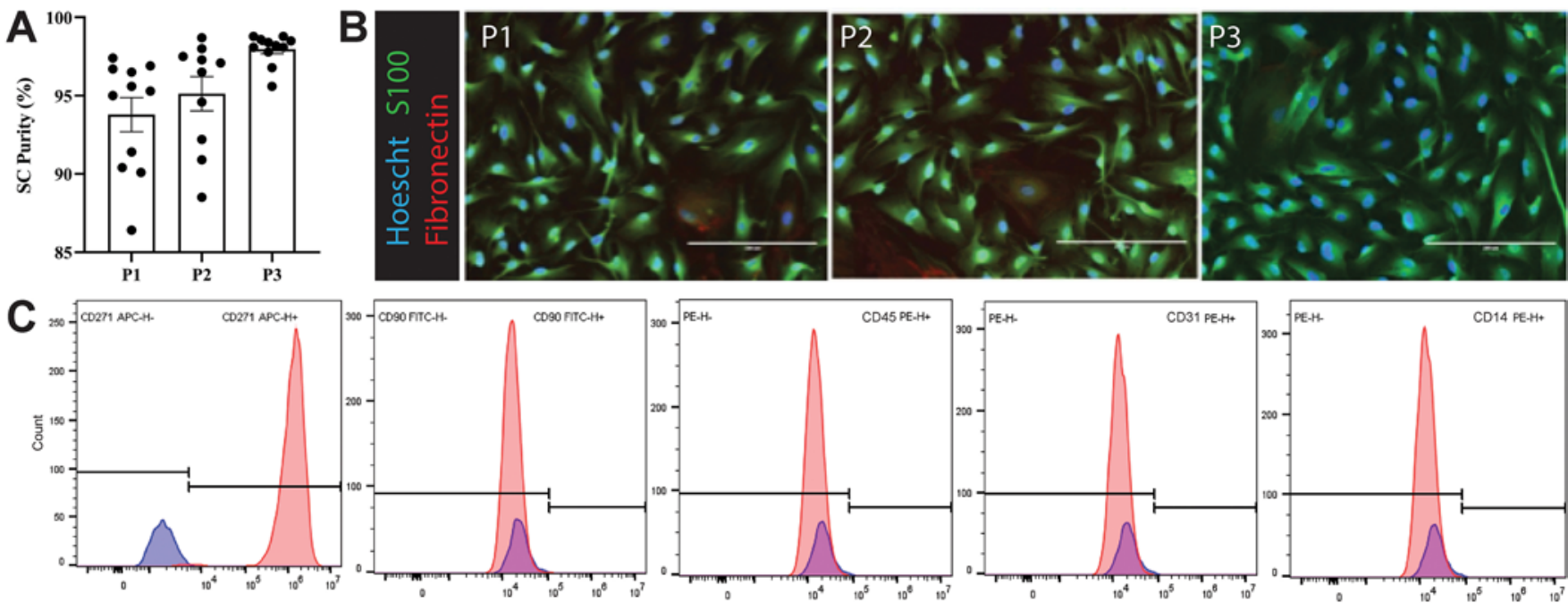

FIG. 4. Purity of SC cultures. A: The purity of nearly all SC products was maintained above $90 \%$ in nearly all passages. B: Representative images of S100-positive SCs at all passages. Very minimal fibroblasts were seen in P2 and none in P3. Bar $=100 \mu \mathrm{m}$. C: Representative images of SC flow cytometry at final harvest and the average of each phenotype marker at each passage. All cells showed a high expression of CD271 and low expression of CD90, CD45, CD31, and CD14.

Residual levels of gentamicin, laminin, and BSA (an indicator for FBS) were very low, in the $\mathrm{pg} / \mathrm{ml}$ range (Supplementary Table 2). Similarly, results of the residual levels of heregulin indicated that the third wash medium did not contain physiologically active heregulin or other polypeptide growth factors including platelet-derived growth factor, insulin-like growth factor, fibroblast growth factor, or undefined mitogenic factors from serum at concentrations able to trigger the activation of ErbB3, ERK, or Akt in SCs (Fig. 5, right; data for two more donors in Supplementary Fig. 1). These results strongly support the conclusion that the third wash medium is devoid of any mitogenic activity.

\section{Discussion}

We have described our methods for a reliable CGMPcompliant scale-up production of autologous human SCs for clinical treatment. Among the $18 \mathrm{SC}$ products that were manufactured using this process, we observed significant improvements in the average yield at every passage from P0 to P3, while maintaining optimal viability $(\geq 80 \%$ ) throughout the production process. Therefore, we believe that these SC harvesting methods allow the capacity for a patient-specific scale-up production.

The SC harvesting and manufacturing methods presented in this paper represent 3 decades of research in developing and refining our SC culturing and transplantation techniques for adjunctive therapy in SCI and peripheral nerve repair. ${ }^{38-40}$ The first critical step that was demonstrated in our institution was the ability to procure SCs from adult rat, primate, and human nerves in the early 1990s. This was followed by a few studies that highlighted the ability of human SCs to expand in number in response to exogenous mitogens, ${ }^{41,42}$ such as heregulin $\beta 1$ and forksolin, while retaining their functional capacity (i.e., formation of myelin). ${ }^{40,41}$ In addition, several preclinical studies assessing long-term survival, proliferation, and tumorgenicity of the SC product have been carried out and published as part of the development of these techniques. ${ }^{2,22,43}$ Our extensive experience with SC cultures in various animal studies, and more recently in clinical trials as a therapy for S-SCIs, CSCIs, and large-gap PNIs, has allowed for substantial refinement of our techniques for culture expansion of these cells.

Evaluating the stability of SCs after preparing for clinical use is crucial in determining the expiration time for the product and complying with FDA regulations..$^{29}$ Because it is important to transplant the SCs before their viability starts to decline, an expiration time must always be determined and provided. In our pretrial product assessment experiments, we demonstrated that the final SC products maintain a stable viability up to 8 hours postrelease and after injection. In addition, the SCs produced were genetically stable. Lastly, the culture media used after enzymatic dissociation retained minimal residual levels of gentamicin, laminin, and BSA (an indicator of FBS), confirming the safety of our product for transplantation.

Following nerve harvest, the SC-containing fascicles are carefully removed from their epineurial sheaths and other connective tissue. Placement into Leibovitz's L-15 medium ensures that fascicles will not adhere to the tissue culture solid-phase plastic substrate, and the SCs begin to separate from axonal debris and myelin within the nerve segments. After a week, the fascicle segments are enzymatically dissociated and plated as adherent monolayers onto laminin-coated plastic flasks. Adequate nerve length and fascicle volume are important factors for a successful SC harvest. Indeed, we observed that longer harvest lengths and larger PFVs correlated with larger yields at P0 and P1. In addition, careful removal of the fascicles without epineural sheath contaminants is essential in producing SCs with high purity in the early passages.

The next major phase is the monolayer expansion that is 


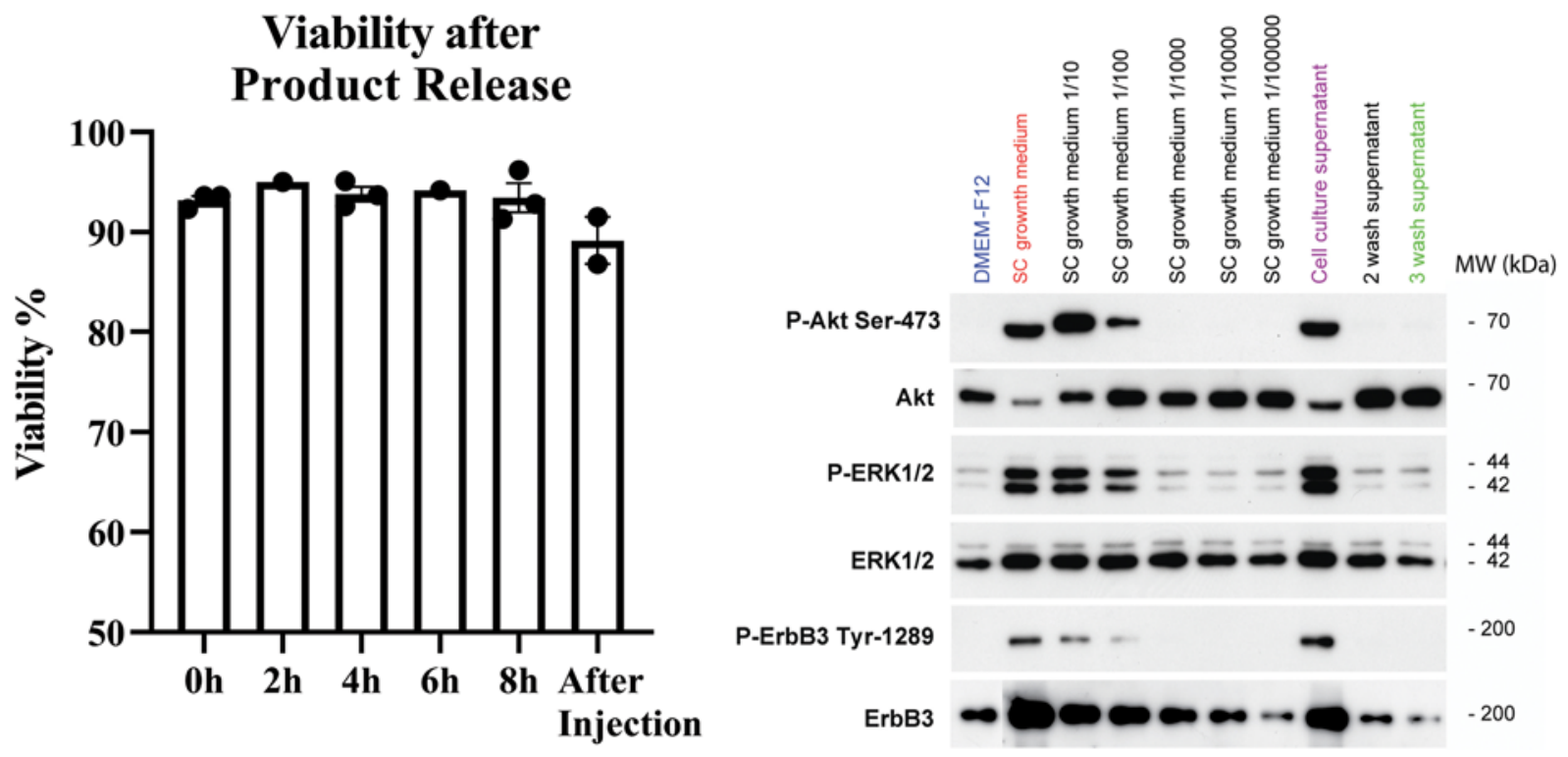

FIG. 5. Left: Pretrial SC product assessment. Assessments were made using SCs cultured from sural nerves of 3 cadaver donors. Product stability measured by viability at the time of release $(0 \mathrm{~h})$ and at $2,4,6$, and 8 hours after release, and postinjection at 8 hours after release. Viability was sustained at all time points. Right: Specific antibodies recognizing the total and phosphorylated forms of ERK1/2 on tyrosine-204 (P-ERK1/2), Akt on serine-473 (P-Akt Ser-473), and ErbB3 on tyrosine-1289 (P-ErbB3 Tyr-1289) were used to detect heregulin residuals in SCs from the donors. Stimulation of SCs with DMEM/F12 served as a negative control (blue) for the detection of basal levels of ErbB3, ERK, and Akt phosphorylation. SC growth medium (red) was used as a positive control for maximal stimulation, and the serial dilutions of this medium in DMEM/F12 (from 1:10 to 1:100,000) generated a standard curve for dose-dependent responses to phosphorylation. Cells stimulated with the cell culture supernatant (purple) served as an additional positive control to assess the bioactivity of the culture media from the human SCs before trypsinization.

achieved by seeding at a modest density and then harvesting at a confluence of $70 \%-80 \%$ so that cell division is not inhibited through cell-cell contact. In general, we observed that 2-3 passages generate adequate cell numbers (an average of approximately 84 million cells at P2 and approximately 151 million cells at P3) for clinical application, backup cryopreservation, and release testing. A series of wash steps is essential to prepare the SC product for release by reducing the concentration of serum and growth factors used in their manufacture. The final cell product is a suspension with excellent handling properties, which includes reversible settling, the absence of clumping, even flow rates, and the ability to insinuate to complex injury volumes.

Obtaining a greater number of viable cells in the final product is crucial when transitioning to $\mathrm{SC}$ transplantation into patients with C-SCI. In these participants, the number of cells was not the priority, but rather a fixed concentration in which the transplanted volume was limited by the size of the cavity. In addition to the linear correlation between length of harvested nerve and cell yield at P0 and P1, we also observed that with our culture techniques, an appreciable increase in cell number occurred at every passage regardless of nerve length. When normalized for a 5-cm nerve harvest, expansion rates increased at every subsequent passage, with the fastest rate of expansion occurring between P2 and P3. This highlights the reliability of our methods for procuring large populations of SCs from relatively small peripheral nerve samples.

The three products processed for individuals with PNI had sural nerve harvests obtained after initial trauma. However, the first patient with PNI had an additional sciatic nerve biopsy from the proximal nerve segment during the initial trauma visit that underwent SC harvesting separately from the sural nerve. Interestingly, despite its traumatic origin, the SC cultures of the sciatic nerve segment maintained a viability above $90 \%$ at all passages. In addition, the purity remained above $95 \%$ for cultures P1-P3, with a final purity of $99.3 \%$ prior to transplantation. This demonstrates the capability of obtaining good viability and purity in SC cultures from both uninjured and injured nerves using these harvesting techniques.

The techniques and methods reported here have undergone years of refinement and optimization. The first three products manufactured after approval of the IND did not reach a purity $>80 \%$ at $\mathrm{P} 1$. These products underwent a panning process in which cells were plated into $10-\mathrm{cm}$ dishes for 15 minutes, where fibroblast will adhere rapidly; then, the supernatants were collected for plating as P1 SCs to increase cell purity, which significantly reduced the yield at the time of transplantation. As a result, we optimized our methods on stripping of the epineurium and pulling fascicles to minimize the presence of contaminants responsible for reducing the purity at $\mathrm{P} 0$. The panning technique was omitted after all subsequent cultures maintained a purity $>80 \%$ and allowed a higher yield at $\mathrm{P} 1$ and all subsequent passages.

Additional studies showed that it was safe to take cells to further passages (P3-P5 were assessed but not presented) for clinical applications based on cell viability, expan- 
sion, phenotype, and genetic stability. Studies also showed no changes in cell phenotype and genetic structure as well as cell viability and counts following cryopreservation (not presented). Cryopreservation at P1 allowed flexibility by extending the period between preparation of the product and the date of transplantation. In the event of any technical issues with cell production or complications with the participants, the cryopreserved cells served as backup to complete the transplantation. These strategies were validated with the additional validation runs to qualify a new manufacturing facility, where most of the manufacturing phase took place.

\section{Conclusions}

We presented a reliable and reproducible method of manufacturing large quantities of autologous SCs for clinical applications. Using these techniques, we produced progressively larger cell populations at each passage with stable viability and purity that was sustained up to 8 hours postrelease and after transplantation. Producing highquality cellular products in large quantities is essential to evaluate their efficacy for the desired indication and also to allow the potential for maximum benefit in patients receiving the therapy.

\section{Acknowledgments}

We would like to acknowledge all of the other members of spinal cord injury research for their contribution, including Dr. Paula Monje, Dr. Katie Gant, Dr. George Jimsheleishvili, Ms. Maria Amador, and Mr. Anil Lalwani. We acknowledge the University of Miami Tissue Bank for providing us cadaver sural nerves for our validation studies. This work to develop SC production methods occurred over several years and was funded by the NIHNINDS (grant no. 1R21NS111334-01), The Miami Project to Cure Paralysis, the Buoniconti Fund, and the Christopher and Dana Reeve Foundation International Research Consortium.

\section{References}

1. Nomura $\mathrm{H}$, Tator $\mathrm{CH}$, Shoichet MS. Bioengineered strategies for spinal cord repair. J Neurotrauma. 2006;23(3-4):496-507.

2. Bastidas J, Athauda G, De La Cruz G, et al. Human Schwann cells exhibit long-term cell survival, are not tumorigenic and promote repair when transplanted into the contused spinal cord. Glia. 2017;65(8):1278-1301.

3. Deng LX, Deng P, Ruan Y, et al. A novel growth-promoting pathway formed by GDNF-overexpressing Schwann cells promotes propriospinal axonal regeneration, synapse formation, and partial recovery of function after spinal cord injury. J Neurosci. 2013;33(13):5655-5667.

4. Deng LX, Hu J, Liu N, et al. GDNF modifies reactive astrogliosis allowing robust axonal regeneration through Schwann cell-seeded guidance channels after spinal cord injury. Exp Neurol. 2011;229(2):238-250.

5. Xu XM, Guénard V, Kleitman N, et al. A combination of BDNF and NT-3 promotes supraspinal axonal regeneration into Schwann cell grafts in adult rat thoracic spinal cord. Exp Neurol. 1995;134(2):261-272.

6. Xu XM, Guénard V, Kleitman N, Bunge MB. Axonal regeneration into Schwann cell-seeded guidance channels grafted into transected adult rat spinal cord. J Comp Neurol. 1995; 351(1):145-160.

7. Cerqueira SR, Lee YS, Bunge MB. A culture model to study neuron-Schwann cell-astrocyte interactions. In: Monje PV,
Kim HA, eds. Schwann Cells: Methods and Protocols. Springer New York; 2018:269-279.

8. Deng LX, Walker C, Xu XM. Schwann cell transplantation and descending propriospinal regeneration after spinal cord injury. Brain Res. 2015;1619:104-114.

9. Kanno H, Pressman Y, Moody A, et al. Combination of engineered Schwann cell grafts to secrete neurotrophin and chondroitinase promotes axonal regeneration and locomotion after spinal cord injury. J Neurosci. 2014;34(5):1838-1855.

10. Lee YS, Wu S, Arinzeh TL, Bunge MB. Enhanced noradrenergic axon regeneration into schwann cell-filled PVDF-TrFE conduits after complete spinal cord transection. Biotechnol Bioeng. 2017;114(2):444-456.

11. Pearse DD, Bastidas J, Izabel SS, Ghosh M. Schwann cell transplantation subdues the pro-inflammatory innate immune cell response after spinal cord injury. Int J Mol Sci. 2018; 19(9):2550.

12. Walker CL, Liu NK, Xu XM. PTEN/PI3K and MAPK signaling in protection and pathology following CNS injuries. Front Biol (Beijing). 2013;8(4):421-433.

13. Wang $\mathrm{X}, \mathrm{Xu} \mathrm{XM}$. Long-term survival, axonal growth-promotion, and myelination of Schwann cells grafted into contused spinal cord in adult rats. Exp Neurol. 2014;261:308-319.

14. Williams RR, Henao M, Pearse DD, Bunge MB. Permissive Schwann cell graft/spinal cord interfaces for axon regeneration. Cell Transplant. 2015;24(1):115-131.

15. Williams RR, Pearse DD, Tresco PA, Bunge MB. The assessment of adeno-associated vectors as potential intrinsic treatments for brainstem axon regeneration. J Gene Med.2012; 14(1):20-34.

16. Assinck P, Duncan GJ, Hilton BJ, et al. Cell transplantation therapy for spinal cord injury. Nat Neurosci. 2017;20(5): 637-647.

17. Fortun J, Hill CE, Bunge MB. Combinatorial strategies with Schwann cell transplantation to improve repair of the injured spinal cord. Neurosci Lett. 2009;456(3):124-132.

18. Tetzlaff W, Okon EB, Karimi-Abdolrezaee S, et al. A systematic review of cellular transplantation therapies for spinal cord injury. J Neurotrauma. 2011;28(8):1611-1682.

19. Bunge MB. Efficacy of Schwann cell transplantation for spinal cord repair is improved with combinatorial strategies. $J$ Physiol. 2016;594(13):3533-3538.

20. Levi AD, Burks SS, Anderson KD, et al. The use of autologous Schwann cells to supplement sciatic nerve repair with a large gap: first in human experience. Cell Transplant. 2016; 25(7):1395-1403.

21. Anderson KD, Guest JD, Dietrich WD, et al. Safety of autologous human Schwann cell transplantation in subacute thoracic spinal cord injury. J Neurotrauma. 2017;34(21):2950-2963.

22. Guest J, Santamaria AJ, Benavides FD. Clinical translation of autologous Schwann cell transplantation for the treatment of spinal cord injury. Curr Opin Organ Transplant. 2013;18(6): 682-689.

23. Dietrich WD. The safety of ahSC in chronic SCI with rehabilitation. NCT02354625. ClinicalTrials.gov. Accessed March 12, 2021. https://ClinicalTrials.gov/show/ NCT02354625

24. Dietrich WD. Safety of autologous human Schwann cells (ahSC) in subjects with subacute SCI. NCT01739023. ClinicalTrials.gov. Accessed March 12, 2021. https:// ClinicalTrials.gov/show/NCT01739023

25. Dietrich WD. Autologous human Schwann cells in peripheral nerve repair. NCT03999424. ClinicalTrials.gov. Accessed March 12, 2021. https://clinicaltrials.gov/ct2/show/ NCT03999424

26. Gersey ZC, Burks SS, Anderson KD, et al. First human experience with autologous Schwann cells to supplement sciatic nerve repair: report of 2 cases with long-term follow-up. Neurosurg Focus. 2017;42(3):E2. 
27. Current good tissue practice requirements. $21 \mathrm{CFR} \$ 1271.150$ (2018).

28. Current good tissue practice. 21 CFR $\$ 1271$ Subpart D (2018).

29. Additional requirements for established described in \$1271.10. 21 CFR §1271 Subpart E (2018).

30. Donor eligibility. 21 CFR $\$ 1271$ Subpart C (2018).

31. Guidance for Industry. CGMP for Phase 1 Investigational Drugs. US Department of Health and Human Services; 2008. Accessed March 12, 2021. https://www.fda.gov/media/70975/ download

32. Fernandez-Valle C, Bunge RP, Bunge MB. Schwann cells degrade myelin and proliferate in the absence of macrophages: evidence from in vitro studies of Wallerian degeneration. $J$ Neurocytol. 1995;24(9):667-679.

33. Sterility. 21 CFR $\$ 610.12$ (2011).

34. Guidance for Industry Pyrogen and Endotoxins Testing: Questions and Answers. US Department of Health and Human Services; 2012. Accessed March 12, 2021. https:// www.fda.gov/regulatory-information/search-fda-guidancedocuments/guidance-industry-pyrogen-and-endotoxins-testing-questions-and-answers

35. Points to Consider in the Characterization of Cell Lines Used to Produce Biologicals. Docket No. 84N-0154. Food and Drug Administration, Department of Health and Human Services; 1993. Accessed March 12, 2021. https://www.fda. gov/media/76255/download

36. Guidance for Industry. Providing Regulatory Submissions to CBER in Electronic Format - Investigational New Drug Applications (INDS). US Department of Health and Human Services, Food and Drug Administration, Center for Biologics Evaluation and Research (CBER); 2002. Accessed March 12, 2021. https://www.fda.gov/media/76466/download

37. Characterization and Qualification of Cell Substrates and Other Biological Materials Used in the Production of Viral Vaccines for Infectious Disease Indications. US Department of Health and Human Services, Food and Drug Administration, Center for Biologics Evaluation and Research; 2010. Accessed March 12, 2021. https://www.fda.gov/regulatory-information/search-fda-guidance-documents/characterizationand-qualification-cell-substrates-and-other-biologicalmaterials-used-production

38. Levi AD. Characterization of the technique involved in isolating Schwann cells from adult human peripheral nerve. $J$ Neurosci Methods. 1996;68(1):21-26.

39. Morrissey TK, Kleitman N, Bunge RP. Isolation and functional characterization of Schwann cells derived from adult peripheral nerve. J Neurosci. 1991;11(8):2433-2442.

40. Levi AD, Guénard V, Aebischer P, Bunge RP. The functional characteristics of Schwann cells cultured from human peripheral nerve after transplantation into a gap within the rat sciatic nerve. J Neurosci. 1994;14(3 pt 1):1309-1319.
41. Levi AD, Bunge RP. Studies of myelin formation after transplantation of human Schwann cells into the severe combined immunodeficient mouse. Exp Neurol. 1994;130(1):41-52.

42. Levi AD, Bunge RP, Lofgren JA, et al. The influence of heregulins on human Schwann cell proliferation. J Neurosci. 1995; 15(2):1329-1340.

43. Bunge MB, Monje PV, Khan A, Wood PM. From transplanting Schwann cells in experimental rat spinal cord injury to their transplantation into human injured spinal cord in clinical trials. Prog Brain Res. 2017;231:107-133.

\section{Disclosures}

Dr. Levi receives teaching honorarium from the AANS and grant support from the US Department of Defense and the National Institutes of Health (NIH-NINDS). Mrs. Khan discloses a relationship with AssureImmune Cord Blood Bank, Aceso Therapeutic, and AX Biotech that includes equity. Drs. Levi, Dietrich, Guest, Pearse, and Bunge have disclosed a relationship with Aceso Therapeutic that includes equity.

\section{Author Contributions}

Conception and design: Khan, Burks, Athauda, Wood, Anderson, Bunge, Pearse, Dietrich, Guest, Levi. Acquisition of data: Brooks, Burks, Athauda, Wood, Silvera, Donaldson, Pressman, Anderson, Bunge, Pearse, Dietrich, Guest, Levi. Analysis and interpretation of data: Brooks, Athauda, Silvera, Donaldson. Drafting the article: Khan, Brooks, Burks, Athauda, Lee. Critically revising the article: Khan, Diaz, Brooks, Lee. Reviewed submitted version of manuscript: Khan, Diaz, Brooks, Lee, Levi. Statistical analysis: Diaz. Administrative/technical/material support: Khan, Athauda, Wood, Anderson, Bunge, Pearse, Dietrich, Guest, Levi. Study supervision: Khan, Anderson, Levi. Clinical manufacture center director: Khan.

\section{Supplemental Information Online-Only Content}

Supplemental material is available with the online version of the article.

Supplementary Tables 1-2 and Fig. 1. https://thejns.org/doi/ suppl/10.3171/2020.11.SPINE201433.

\section{Correspondence}

Aisha Khan: Interdisciplinary Stem Cell Institute, Miami Project to Cure Paralysis, University of Miami Miller School of Medicine, Miami, FL. akhan@med.miami.edu. 